\title{
Second-order conditioning of the rabbit's nictitating membrane response as a function of the CS2-CS1 and CS1-US intervals
}

\author{
E. JAMES KEHOE, ANNE-MARIE FEYER, and JENNIFER L. MOSES \\ University of New South Wales, Kensington, New South Wales 2033, Australia
}

\begin{abstract}
Three experiments investigated conditioning of the rabbit's nictitating membrane response (NMR) in a second-order conditioning procedure which intermixed first-order trials (CS1-US) and second-order trials (CS2-CS1) from the outset of training. Experiment 1 provided a controlled demonstration that substantial levels of second-order conditioning can be obtained with the NMR preparation. Experiment 2 showed that the level of CR acquisition to CS2 was an inverse function of the CS2-CS1 interval over the values of 400,800 , and 2,400 msec. Experiment 3 found that CR acquisition to CS2 and CS1 in second-order conditioning varied in a parallel fashion across CS1-US intervals. Similarly, Experiment 3A found that the level of CR acquisition to the two components of a serial compound (CSA-CSB-US) varied in a parallel fashion as a function of the CSB-US interval. The results of the CS2-CS1 and CS1-US interval manipulations were all predictable from the known CS-US interval effects in NMR conditioning with a single CS. The present results are discussed with regard to their implications for accounts of serial compound conditioning and second-order conditioning.
\end{abstract}

The present experiments stemmed from theoretical questions which arose from previous research which examined conditioning of the rabbit's nictitating membrane response (NMR) in reinforced serial compounds (CSA-CSB-US). ${ }^{1}$ In the rabbit NMR preparation, a serial compound procedure substantially enhances responding to the initial stimulus (CSA) even when it is temporally remote from both CSB and the US (Kehoe, Gibbs, Garcia, \& Gormezano, 1979). To identify the mechanisms which contribute to CR acquisition in a serial compound, research has focused on three interstimulus relations in serial compounds, viz., CSA-CSB, CSA-US, and CSB-US (Gormezano $\&$ Kehoe, in press; Kehoe et al., 1979). A consideration of the interstimulus relations reveals that there are five broad classes of mechanisms which could contribute in a cumulative fashion to $C R$ acquisition to CSA in a serial compound. Moreover, each class of mechanism can be tied to a specific combination of the interstimulus relations. In brief, the possible mechanisms and their requisite interstimulus relations are as follows:

(1) Direct conditioning of CSA requires only CSAUS pairings and can be varied through manipulation of the CSA-US interval.

(2) Stimulus generalization requires only CSB-US

This research was supported by the School of Psychology, University of New South Wales, and the Australian Research Grants Committee. The assistance of Nancy Amodei is gratefully acknowledged. Requests for reprints should be sent to E. James Kehoe, School of Psychology, University of New South Wales, P.O. Box 1, Kensington, New South Wales 2033, Australia. pairings, plus sporadic test presentations of CSA to observe generalized responses.

(3) General transfer is distinct from stimulus generalization and requires both CSA-US and CSB-US pairings. A general transfer mechanism can be conceptualized as a learning-to-learn process analogous to that found in discrimination learning in which acquisition of an "easy" discrimination facilitates acquisition of a "hard" discrimination (e.g., Pavlov, 1927, pp. 121-122; Seraganian, 1979). Similarly, CR acquisition to CSB with its short CS-US interval could facilitate CR acquisition to CSA with its longer, otherwise ineffective CS-US interval. In practice, the use of intermixed CSA-US and CSB-US pairings provides a joint estimate of direct conditioning of CSA, stimulus generalization, and any general transfer from CSB to CSA. With such "uncoupled" CSA-US and CSB-US training, the levels of responding to CSA have reached only $20 \%-40 \%$ CRs, appreciably below the levels of $60 \%-80 \%$ CRs to CSA obtained in comparable serial compounds (Gormezano \& Kehoe, in press, Experiment 6; Kehoe et al., 1979, Experiment 3).

(4) Associative transfer relies on the CSA-CSB and CSB-US pairings in a serial compound. Hypotheses about associative transfer are based on the phenomena of second-order conditioning (Frey, Englander, \& Roman, 1971; Rescorla, 1973, p. 145) and sensory preconditioning (Wickens, 1959, 1965, 1973), both of which actually involve procedurally separate CSACSB and CSB-US pairings. To date, the evidence for associative transfer in serial compounds has been 
largely indirect, based on the comparisons between serial compound and "uncoupled" training (Gormezano \& Kehoe, in press; Kehoe et al., 1979). Direct evidence of associative transfer using secondorder or sensory preconditioning procedures with the rabbit NMR preparation has been rare (Gormezano $\&$ Kehoe, in press).

(5) Serial stimulus mediation relies on the integrity of the entire CSA-CSB-US sequence which composes a reinforced serial compound. Such a process would not entail associative transfer from CSB to CSA. Instead, CSB may be thought to "bridge" the long CSA-US interval, effectively foreshortening it. However, at present, the hypothesis of serial stimulus mediation represents a logical possibility, which can gain support only indirectly by the elimination of other possibilities.

The present experiments examined the determinants of associative transfer in relative isolation from the other mechanisms which may operate in serial compound conditioning. In particular, the present experiments used a procedure in which separate CSA-CSB and CSB-US trials were intermixed from the outset of training. Breaking the serial compound into separate CSA-CSB and CSB-US pairings eliminated any contribution by direct conditioning of CSA, general transfer, and serial mediation, leaving only associative transfer and stimulus generalization as the possible contributors to $\mathrm{CR}$ acquisition to CSA. In studies of second-order conditioning and sensory preconditioning, their respective CS-CS and CS-US pairings have been sequenced into two distinct stages. However, serial compound procedures do not contain a discrete sequence of CS-CS pairings at one time and CS-US pairings at another. Hence, to approximate more closely the circumstances of serial compound conditioning, the present experiments were carried out in a single stage which entailed randomly intermixing CSA-CSB and CSB-US trials. Since many contemporary examinations of second-order conditioning intersperse second-order trials (CS2-CS1) with first-order "refresher" trials (CS1-US), the use of a single stage corresponds exactly to the second phase of current procedures (cf. Maisiak \& Frey, 1977; Rashotte, Griffin, \& Sisk, 1977; Rescorla, 1973, 1980). To acknowledge this correspondence in procedure, the nomenclature of second-order conditioning will be used in the description of the methods and results of the present experiments.

The aims of the present experiments extended beyond sheer demonstration of associative transfer with the NMR preparation. While Experiment 1 was a controlled demonstration of second-order conditioning, subsequent experiments examined the role of interstimulus contiguity in second-order conditioning by manipulating the CS2-CS1 and CS1-US intervals.
Specifically, Experiment 2 examined the effects of the CS2-CS1 interval to determine whether they paralleled the broad effects seen in serial compounds (Kehoe et al., 1979, Experiment 1) or the sharp "contiguity gradient" obtained in first-order conditioning (cf. Gormezano, 1972). Experiments 3A and 3B were tandem investigations of CS-US interval effects in serial compound conditioning and secondorder conditioning, respectively. Specifically, Experiment $3 \mathrm{~A}$ examined the effects of the CSB-US interval on CR acquisition to CSA, and Experiment $3 B$ examined the effects of the CS1-US interval on CR acquisition to CS2.

\section{EXPERIMENT 1}

Experiment 1 was conducted to provide a wellcontrolled demonstration of associative transfer in the rabbit NMR preparation. There were three groups. Group PP was the second-order conditioning group, which received both CS2-CS1 and CS1-US pairings. Group PU, which controlled for stimulus generalization from CS1 to CS2, received CS1-US pairings interspersed with "unpaired" presentations of CS2 and CS1. Group UP, which controlled for any unconditioned stimulus properties of CS1, received unpaired presentations of the CS1 and US mixed with CS2-CS1 pairings. Moreover, both Groups PU and UP controlled for any nonassociative contributions arising from US presentations.

There has been some ambiguity regarding the robustness of associative transfer in rabbit preparations. On one hand, Gormezano and Kehoe (in press, Experiment 5) found that intermixed CS2-CS1 and CS1-US pairings yielded modest levels of responding to CS2 (terminal mean $=28 \% \mathrm{CRs}$ ), which were significantly higher than either the corresponding PU or UP control conditions (means $<10 \% \mathrm{CRs}$ ). On the other hand, Frey and his associates, who measured responding of the outer eyelids, have been unable to obtain appreciable levels of responding to CS2 (Maisiak \& Frey, 1977; Popik, Stern, \& Frey, 1979; Sears, Baker, \& Frey, 1979). Consequently, the present experiment was conducted to confirm the positive results obtained previously with the NMR preparation. The only major change from the procedure of Gormezano and Kehoe (in press) was the use of a CS2-CS1 interval of $400 \mathrm{msec}$, which was shorter than the $1,400-\mathrm{msec}$ value used previously.

\section{Method}

\section{Subjects}

The subjects were 24 naive male and female albino rabbits (Oryctolagus cuniculus). On arrival, each rabbit was $70-80$ days old and weighed about $1.5 \mathrm{~kg}$. Each rabbit had free access to food and water in its home cage at all times. 


\section{Apparatus}

The apparatus and recording procedure for the nictitating membrane response were essentially the same as those described by Gormezano (1966). The subjects were trained in eight individual conditioning chambers (interior dimensions: $42 \times 71 \times 33 \mathrm{~cm}$ ), which were located in a room adjacent to that which housed programming and recording equipment. The walls and ceiling of each chamber were chipboard, lined with fiberglass and pitted aluminum sheeting, which acoustically isolated each subject. On the wall in front of the subject was located a stimulus panel, and in the wall behind the subject was an exhaust fan. A speaker was mounted at the midpoint of the stimulus panel, $8 \mathrm{~cm}$ anterior to and $16 \mathrm{~cm}$ above the subject's head. The speaker provided both white noise and an auditory CS, which was a 1,000-Hz, 88-dB (re: $20 \mu \mathrm{N} / \mathrm{m}^{2}$ ) tone superimposed on 82-dB background noise provided by the white noise and the exhaust fan. Mounted on the stimulus panel, $4 \mathrm{~cm}$ above the speaker, was an $8-W$ frosted neon light tube, which served as a houselight and provided an interior illumination of $700 \mathrm{~lx}$ at the subject's eye level. To provide a visual $\mathrm{CS}$, the light was flashed at a rate of $20 \mathrm{~Hz}$, which was controlled by a circuit adapted from a tachistoscope. The US was a 50-msec, 3-mA, 50-Hz ac shock delivered via stainless steel Autoclip wound clips positioned $10 \mathrm{~mm}$ apart and $15 \mathrm{~mm}$ posterior to the dorsal canthus of the right eye. The shock intensity was controlled by a Coulburn Instruments shocker-distributor. The sequence and timing of stimulus events on each trial was controlled by a Quipu (Sydney) Digital Controller in conjunction with an ASR-33 Teletype paper-tape reader.

During training, each rabbit was restrained in a Perspex box $(45 \times 14 \times 22 \mathrm{~cm})$. The rabbit was held in place by insertion of its head through an adjustable stock and by fastening its ears to the front of the stock with a polyurethane foam-covered metal clamp. The restraining boxes were held in place within each chamber between metal stays screwed to the floor of a chipboard tray.

Each rabbit's right external eyelids were restrained open by No. 3 tailor-hooks mounted on a Velcro strap which fitted about the head. A muzzle-like headset, fitted securely about the snout, supported a photosensitive transducer for monitoring movements of the nictitating membrane. A small hook was attached to a nylon loop sutured in the nictitating membrane of the rabbit's right eye. The hook was connected by a thread to one end of an L-shaped stainless steel lever, which mechanically transmitted the movement of the nictitating membrane to the transducer. Inside the transducer, movement of the lever rotated a disk of polarized filter, which was interposed between a light-emitting diode and a phototransistor covered by a fixed polarized filter. Thus, rotation of the disk produced changes in the level of illumination reaching the transistor through the fixed filter. The accompanying variations in the electrical signal of the phototransistor were amplified and recorded on a Watanabe (Mark III WTR 331-4C) four-channel ink-writing oscillograph operating at a speed of $50 \mathrm{~mm} / \mathrm{sec}$.

\section{Procedure}

All animals received 1 day of preparation, 1 day of recovery, 1 day of adaptation, and 6 days of acquisition training. On the preparation day, a small loop of silk (000 Dynex) was sutured into the rabbit's right nictitating membrane, the surrounding hair was removed, and the animals were returned to their home cages for 1 day of recovery. On the adaptation day, the US electrodes were applied and the animals were placed in the conditioning apparatus for a period equal to the length of the subsequent training sessions. No programmed stimuli were presented during the adaptation session.

Following the preparation, the animals were assigned randomly to one of three groups $(n=8)$. For the first group, the PP condition, each day of training consisted of 30 first-order trials with a 400-msec CS1-US interval (measured onset to onset), which were randomly interspersed with 30 second-order conditioning trials with a 400-msec CS2-CS1 interval. The second group, PU, received 30 presentations each of CS2-alone, CS1-alone, and CS1-
US. When a CS2 trial and a CS1 trial did occur by chance in sequence, the minimal interval between the two CS onsets was $40 \mathrm{sec}$. The third group, UP, received 30 interspersed presentations of CS2-CS1, CS1-alone, and US-alone. When a CS1 trial and a US trial did occur by chance in sequence, the minimal interval between the onsets of the two stimuli was $\mathbf{4 0} \mathrm{sec}$. For all groups, the trial types were randomly interspersed subject to the restriction that no more than three trials of any one type occur in succession. In addition, all groups received three CS2-alone test trials administered on Trials 20,40 , and 60 . The intertrial intervals for Group PP were varied randomly across 50, 60, and $70 \mathrm{sec}$ (mean $=60 \mathrm{sec}$ ), while the intertrial intervals for Groups PU and UP were $\mathbf{4 0}$ and $\mathbf{5 0} \mathrm{sec}$ to accommodate the greater number of trials within the same length of session as Group PP. The two CSs, tone and light, were counterbalanced within groups such that half the animals received light as CS2 and tone as CS1, while the other half received tone as CS2 and light as CS1.

A response was defined as any extension of the nictitating membrane exceeding $.5 \mathrm{~mm}$ (1 mm of pen deflection). A CR to CS1 was defined as any response initiated after the onset of CSI but before its offset, that is, a response with a latency of less than $400 \mathrm{msec}$ following CS1 onset. Similarly, a CR to CS2 was defined as any response initiated after the onset of CS2 but before its offset. On the three CS2 test trials, a CR was defined as any response occurring with a latency less than $1,400 \mathrm{msec}$ after CS2 onset. To analyze the data, a set of planned orthogonal contrasts was written using the Bonferroni technique (Miller, 1966). The rejection level was set according to a Type I error rate of .05 .

\section{Results}

Figure 1 shows the mean percent CRs to CS1 on CS1-US trials for Groups PP and PU, and on CS1alone trials for Group UP, as a function of days of training. Figure 1 indicates that $C R$ acquisition was similar for Groups PP and PU, which received first-order pairings, reaching maximal levels of approximately $90 \%$ CRs on Day 6. For Group UP, which received no first-order pairings, the level of

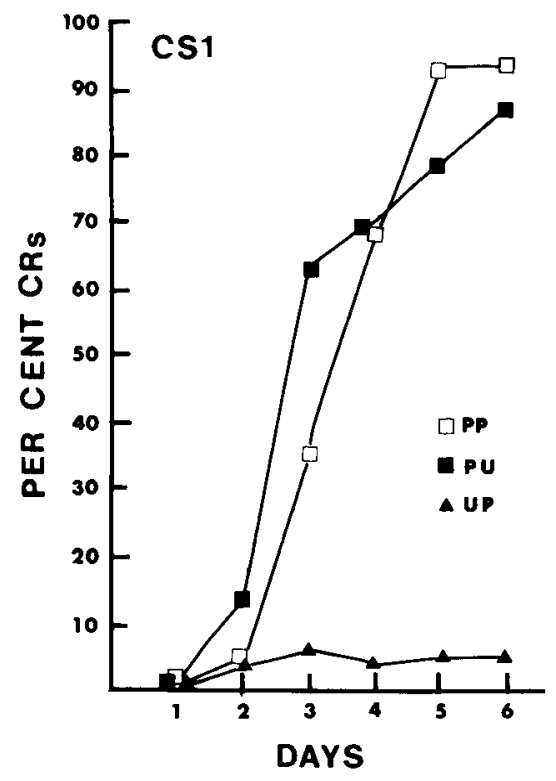

Figure 1. Mean percentage of first-order CRs to CS1 plotted as a function of days for Groups PP, PU, and UP in Experiment 1. 


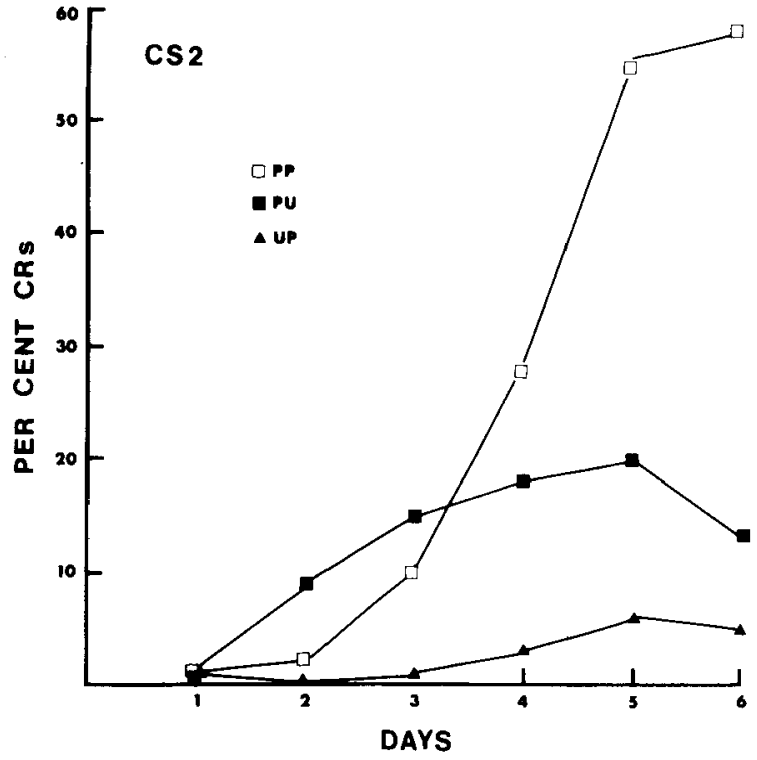

Figure 2. Mean percentage of second-order CRs to CS2 plotted as a function of days for Groups PP, PU, and UP in Experiment 1.

responding hovered around $6 \%$ throughout training.

Figure 2 shows the mean percent CRs that occurred during CS2 on CS2-CS1 trials for Groups PP and UP, and on CS2-alone trials for Group PU, as a function of days of training. Examination of Figure 2 reveals that the PP condition produced the most rapid response acquisition to $\mathrm{CS} 2$ and yielded a terminal level of approximately $60 \%$ CRs on Days 5 and 6 . In contrast, the level of responding to CS2 in the PU condition reached a maximum of only $20 \%$ CRs. The statistical analysis confirmed the divergence in responding between Groups PP and PU in the form of a significant interaction of the PP vs. PU contrast with the linear trend across days $[F(1,29)$ $=27.94$ ] . In the UP condition, there was only a slight semblance of responding to CS2, with a maximum level of responding reaching only $6 \%$ responses on Day 5. The low level of the UP condition relative to the PP condition was statistically confirmed by a main effect contrast between the two conditions $[F(1,29)=37.36]$.

\section{Discussion}

The results of Experiment 1 provide a controlled demonstration of associative transfer which confirms the findings of Gormezano and Kehoe (1981, in press) and agrees with previous demonstrations of second-order conditioning in associative procedures as diverse as conditioned suppression (e.g., Anderson, Plant, Johnson, \& Vandever, 1967; Popik et al., 1979, Experiment 2; Rescorla, 1973, 1980; Szakmary, 1979), Sidman avoidance responding (Herendeen \& Anderson, 1968), taste aversion (Best, Best, \& Mickley,
1973), and autoshaping (e.g., Rashotte et al., 1977). The level of responding to CS2 in the PP group was above that in the PU group. Thus, the CS2-CS1 pairings were essential for a high level of $C R$ acquisition to $\mathrm{CS} 2$, indicating that responding to $\mathrm{CS} 2$ arose from associative processes and not from stimulus generalization from CS1 and/or pseudoconditioning. However, since responding to CS2 in the PU condition did show some systematic rises, it would appear that stimulus generalization, along with the associative transfer process, has a cumulative effect on responding to CS2. The finding of both associative transfer and stimulus generalization from CS1 to CS2 parallels the findings obtained with serial compound conditioning of the rabbit NMR (Gormezano \& Kehoe, in press; Kehoe et al., 1979).

\section{EXPERIMENT 2}

Experiment 2 examined the level of responding to CS2 as a function of the CS2-CS1 interval. While the pairing vs. unpairing of CS2 and CS1 in Groups PP and $\mathrm{PU}$ in Experiment 1 showed that $\mathrm{CR}$ acquisition to CS2 depended on an associative process, the pairingunpairing manipulation represents a relatively crude manipulation of interstimulus contiguity which has historically been the heart of associative theories of conditioning (Gormezano \& Kehoe, 1975, 1981; Rescorla, 1980, p. 40). Thus, the present experiment represented a more refined examination of the role of interstimulus contiguity in second-order conditioning and, more generally, in associative learning.

The impetus for the present experiment arose from a disparity between the effects of CS-US contiguity in first-order conditioning and CSA-CSB contiguity in serial compound conditioning. In the rabbit NMR preparation, manipulations of the CS-US interval have produced well-defined, graded effects on the rate and level of CR acquisition (cf. Gormezano, 1972; Kehoe, 1979): CS-US intervals between 200 and $\mathbf{4 0 0}$ msec produce rapid CR acquisition to an asymptote of virtually $100 \% \mathrm{CRs}$, while longer CSUS intervals yield progressively lower rates and levels of acquisition which reach negligible levels around a value of $4,000 \mathrm{msec}$. In contrast to the sharp "contiguity gradient" for the CS-US interval, CR acquisition to CSA in a serial compound (CSA-CSB-US) appears to be less sensitive to the CSA-CSB interval. In Kehoe et al. (1979, Experiment 1), the CSA-CSB was manipulated across the values of $400,900,1,400$, and $2,400 \mathrm{msec}$. Despite the large differences in the CSA-CSB interval, initial CR acquisition to CSA proceeded at a uniformly rapid rate. Consequently, the present experiment was conducted to determine whether manipulation of the CS2-CS1 interval would yield a steep or a flat contiguity gradient of associative transfer. 
In addition to examining the CS2-CS1 interval, the present experiment entailed a longer period of training, 10 days, to determine whether responding to CS2 would show any decline after reaching a maximum. In examinations of second-order conditioning, it has been found that prolongation of secondorder training leads eventually to a decline in responding, even with CS1-US refresher trials (e.g., Herendeen \& Anderson, 1968; Holland \& Rescorla, 1975). Similarly, in serial compound conditioning, Kehoe et al. (1979) found that the level of responding to CSA showed a slow decline after reaching a maximum. In both cases, the ultimate decline in responding has been construed as indicating the acquisition of an inhibitory potential which counteracts the excitatory effect of associative transfer. In the secondorder conditioning paradigm, the unreinforced CS2$\mathrm{CS} 1$ compound constitutes a $\mathrm{CS}-$, while the reinforced presentation of CS1 constitutes a CS+. Hence, second-order conditioning inherently contains a conditioned inhibition procedure, and thus, CS2 would be expected to acquire inhibitory properties (Herendeen \& Anderson, 1968; Pavlov, 1927, pp. 33, 68-71, 1928, pp. 104-106). In serial compound conditioning, the acquisition of inhibition presumably arises from differential conditioning based on the long CSA-US interval's being contrasted with the shorter CSB-US interval.

\section{Method}

\section{Subjects}

The subjects were 32 naive male and female albino rabbits which, on arrival, were 70-80 days old and weighed about $1.5 \mathrm{~kg}$. All animals were housed individually with free access to food and water.

\footnotetext{
Apparatus and Procedure

Unless otherwise specified, the apparatus, recording technique, and procedure were identical to those used in Experiment 1. All animals received 1 day of preparation, 1 day of recovery, 1 day of adaptation, and 10 days of acquisition training. Following preparation and adaptation, the animals were assigned randomly to one of four groups $(n=8)$ and given 10 days of acquisition training. For all groups, each day of training consisted of 30 reinforced first-order training trials (CSI-US), in which the CS1-US interval was $\mathbf{4 0 0} \mathrm{msec}$. For three of the groups, the CS1-US trials were interspersed with 30 second-order trials (CS2-CS1), subject to the restriction that no more than three trials of any one type occurred in succession. In these three groups, the CS2-CS1 interval was varied across the values of 400,800 , and $2,400 \mathrm{msec}$. For expository purposes, each group was labeled according to its CS2-CS1 interval. The fourth group was identical to Group PU in Experiment 1 and therefore was also designated as "PU." The major feature of Group PU was that it received 30 presentations of CS2-alone and CS1-alone as well as the 30 CS1-US trials. Although the CS2-CS1 relation was manipulated across groups, the duration of both CS2 and CS1 was fixed at $400 \mathrm{msec}$. In Groups 400,800 , and 2,400 , the intertrial interval varied randomly across the values of 50,60 , and $70 \mathrm{sec}($ mean $=60 \mathrm{sec})$. In Group PU, the intertrial intervals were $\mathbf{4 0}$ and $50 \mathrm{sec}$.
}

\section{Results}

CR acquisition on CSI-US trials proceeded in a similar fashion for all four groups. On Day 1, all groups showed a mean level of less than $10 \%$ CRs. Thereafter, responding increased across days and reached an asymptote of approximately $90 \%$ CRs by Day 6.

Figure 3 shows the percentage of CRs that occurred during the $400-\mathrm{msec}$ CS2 on CS2-CS1 trials as function of days of training. The figure reveals that the level of responding to CS2 was an inverse function of the CS2-CS1 interval: The level of responding to CS2 in Group 400 was consistently higher than that of Group 800 , which in turn was consistently higher than that of Group 2,400. Across the 10 days of training, there was an inverse linear relationship in the mean levels of responding to CS2, which were $39 \%, 28 \%$, and $19 \%$ for Groups 400,800 , and 2,400 , respectively $[F(1,28)=12.14]$. Despite the differences in the level of responding to CS2, Groups 400,800 , and 2,400 all showed a similar pattern of initial response acquisition to CS2, to a maximum level between Days 5 and 6, followed by a steady decline. The general acquisition of CRs to CS2 was confirmed by a significant linear trend across days $[F(1,28)=$ 33.83], while a curvature in the acquisition function was confirmed by a significant quadratic trend across days $[F(1,28)=77.77]$. Since responding to CS2 in Groups 400,800 , and 2,400 started at a low level, diverged during initial acquisition, and converged

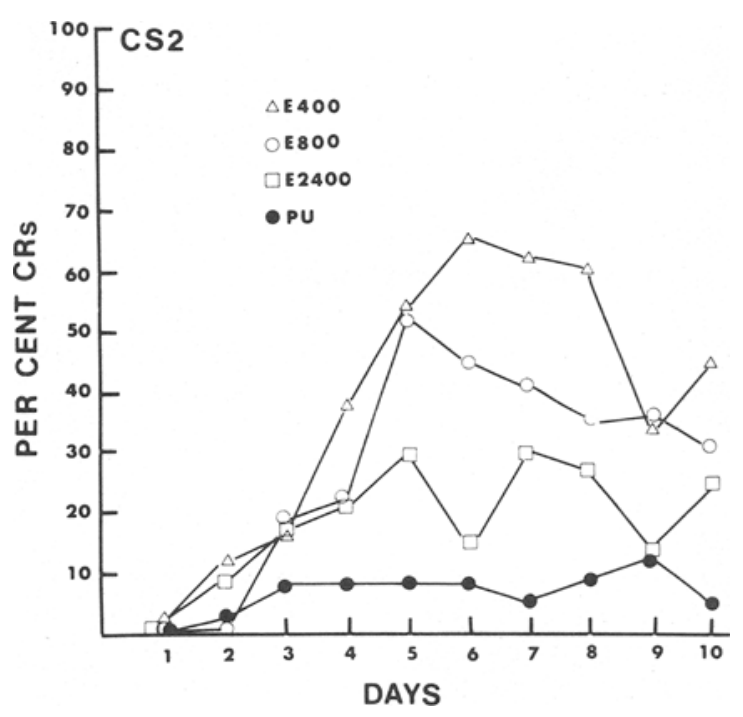

Figure 3. Mean percentage of second-order CRs to CS2 plotted as a function of days for Groups $400,800,2,400$, and PU in Experiment 2. The group labels denote the CS2-CS1 interval in milliseconds. 
again during the subsequent decline in responding to CS2, there was a significant interaction between the CS2-CS1 interval and both the linear trend $[F(1,28)$ $=5.19]$ and the quadratic trend across days $[F(1,28)$ $=12.96$.

Further examination of Figure 3 reveals that the level of responding to CS1 in all three CS2-CS1 groups consistently exceeded that of Group PU, which received explicitly unpaired presentations of CS2 and CS1. In fact, Group PU showed only a slight semblance of responding to $\mathrm{CS} 2$, which rarely exceeded $10 \%$ responses. The higher level of responding in the CS2-CS1 groups relative to the unpaired group was confirmed by a statistical comparison between the average across the three CS2-CS1 groups $(29 \%)$ vs. the mean level of the unpaired group $(10 \%)[F(1,28)$ $=22.43$.

\section{Discussion}

The results of the present experiment replicated the major finding of Experiment 1, viz., that it is possible to obtain appreciable levels of responding to $\mathrm{CS} 2$ in a second-order conditioning procedure in which CS2 is temporally remote from the US. Specifically, the level of responding in the CS2-CS1 groups was consistently higher than that of Group PU, which received no second-order pairings. Since responding to CS2 in the CS2-CS1 groups exceeded that generated by nonspecific transfer, in particular, stimulus generalization, the responding to $\mathrm{CS} 2$ can be attributed to processes of associative transfer based on CS2-CS1 pairings.

In addition to demonstrating the general associative consequences of the CS2-CS1 "pairing," the present findings also revealed that the level of responding that accrued to CS2 was an inverse function of the CS2-CS1 interval. Moreover, the inverse function between CR frequency and CS2-CS1 interval parallels the function between $C R$ frequency and CSUS interval over the same range of values (cf. Gormezano, 1972; Kehoe, 1979; Smith, Coleman, \& Gormezano, 1969). In particular, a CS-US interval of $400 \mathrm{msec}$ is a near-optimal value for conditioning of the rabbit NMR and, likewise, the 400-msec CS2CS1 interval in the present experiment produced the most rapid acquisition and highest level of responding to CS2. Furthermore, investigations with CS-US interval manipulations have found that responding declines across CS-US intervals that exceed $400 \mathrm{msec}$, reaching negligible levels around the value of 4,000 msec. Similarly, responding to CS2 declined at the CS2-CS1 interval of $800 \mathrm{msec}$ and reached a low level at the $2,400-\mathrm{msec}$ value. Thus, there appears to be a strong parallel between the laws of interstimulus contiguity in first- and second-order conditioning (cf. Wickens, 1959, 1965, 1973). Conversely, it would ap- pear that the contiguity gradient for associative transfer from CS1 to CS2 is considerably steeper than the relatively broad gradient obtained with reinforced serial compounds (cf. Kehoe et al., 1979). Although some associative transfer from CS1 to CS2 was evident even at the 2,400-msec CS2-CS1 interval, the absolute level of responding to CS2 was low and seems insufficient to account for the maximum levels of responding to CSA in serial compounds with comparable CSA-CSB intervals.

The pattern of responding across training shown by the three paired groups, that is, an initial increase in responding to CS2 followed by a slow decline, agrees with previous results of second-order conditioning procedures (e.g., Herendeen \& Anderson, 1968; Rescorla, 1973) and serial compound conditioning (Kehoe et al., 1979). The decline in responding to CS2 can be construed as indicating the encroachment of inhibitory processes counter to associative transfer. However, while responding to CS2 was not permanently sustained, it was by no means transient-responding to CS2 rose over the course of 150 to 180 CS2-CS1 trials before any decline became evident. Even at the end of training, that is, after $\mathbf{3 0 0}$ CS2-CS1 trials, the level of responding in the paired groups was still above that of the unpaired group. Since the decline did not lead to a total loss of responding in CS2, it was not possible to submit CS2 to summation and retardation tests which would confirm whether the decline in responding represented the acquisition of inhibitory potential to CS2 or just a reduction in the excitatory potential of CS2 (cf. Rescorla, 1969).

\section{EXPERIMENTS 3A AND 3B}

Experiments $3 \mathrm{~A}$ and $3 \mathrm{~B}$ delineated the effects of CS-US interval manipulations on $C R$ acquisition in serial compound and second-order conditioning procedures. Specifically, Experiment $3 \mathrm{~A}$ examined the rate and level of CR acquisition to CSA and CSB in a serial compound as a function of the CSB-US interval. Similarly, Experiment 3 examined CR acquisition to CS2 and CS1 in second-order conditioning as a function of the CS1-US interval. Together, these two experiments permitted a determination of whether corresponding CS-US manipulations would have parallel or diverging effects in serial compound and second-order conditioning.

In research with serial compounds, there has been some evidence that responding to CSA depends on the associative relation between CSB and the US as manipulated through the CSB-US interval (Frey, Englander, \& Roman, 1971; Kehoe, 1979). However, there has been no comparable evidence in secondorder conditioning. In Experiment 1 of the present series, a comparison between the effects of paired vs. unpaired presentations of CS1 and the US (PP vs. 
UP) demonstrated that initial CR acquisition to CS2 depends in broad terms on the contiguous relation between CS1 and the US. However, it remained to be determined whether quantitative variations in CS1-US contiguity would have graded effects on the level of second-order conditioning.

In Experiment 3A, the CSA-US interval in the serial compounds was fixed at $2,800 \mathrm{msec}$, while the CSB-US interval was manipulated over the values of $0,80,120,160$, and $320 \mathrm{msec}$. The value of the CSAUS interval was selected on the basis of Kehoe et al.'s (1979) finding that a similar value $(2,750 \mathrm{msec})$ by itself produced little direct conditioning of CSA but was susceptible to substantial augmentation in a serial compound. The values of the CSB-US interval were chosen according to the concave-downward function which characterizes the effects of CS-US interval manipulations in the rabbit NMR preparation (Gormezano, 1972; Smith et al., 1969). In brief, a CS-US interval of zero, that is, simultaneous onsets of the CS and US, produces no CR acquisition. As the CS-US interval approaches values between 200 and $400 \mathrm{msec}, \mathrm{CR}$ acquisition becomes increasingly rapid and reaches progressively higher asymptotic levels, while CS-US intervals longer than $400 \mathrm{msec}$ produce decreasing rates and levels of $C R$ acquisition. By selecting CSB-US intervals between 0 and $320 \mathrm{msec}$, it was possible to produce a full range of CR acquisition curves while minimizing alterations in the CSA-CSB interval. According to the findings of Kehoe et al. (1979), the rate of CR acquisition to CSA was relatively uniform over CSA-CSB intervals ranging from 400 to $2,400 \mathrm{msec}$. Since the variation in the CSA-CSB interval in the present experiment ranged from 2,480 to $2,800 \mathrm{msec}$, it seemed unlikely that these small alterations in the CSA-CSB interval would have any discernible effect on the level of responding to CSA.

In Experiment 3B, the CS2-CS1 interval was fixed at $400 \mathrm{msec}$, which Experiment 2 indicated was an optimal value for second-order conditioning, while the CS1-US intervals were $100,140,160,320$, and $400 \mathrm{msec}$. The two lower values, 100 and 140 , were slightly longer than their counterparts in Experiment $3 \mathrm{~A}$ in order to facilitate the rate of first-order conditioning. The value of $400 \mathrm{msec}$ was added to provide a point of replication with Group PP in Experiment 1 and Group 400 in Experiment 2.

\section{Method}

\section{Subjects}

On arrival, the rabbits were 70-80 days old and weighed about $1.5 \mathrm{~kg}$. All animals were housed individually with free access to food and water.

\section{Apparatus and Procedure}

Unless otherwise specified, the apparatus, recording technique, and procedure were identical to those used in Experiment 1.
Experiment 3A. Following preparation and adaptation, the rabbits were randomly assigned to five groups $(n=8)$ and given 14 days of acquisition training with a serial compound (CSACSB-US). For all groups, the CSA-US interval was held constant at $2,800 \mathrm{msec}$, and CSA's duration was $400 \mathrm{msec}$. The groups were trained at CSB-US intervals of $0,80,120,160$, and $320 \mathrm{msec}$, respectively. For expository purposes, each group was labeled with an "S" (to denote the serial compound) and the value of the CSB-US interval. CSB's duration covaried with the CSB-US interval and overlapped the 50-msec US presentation. Accordingly, the durations of CSB across the five groups were 50,130,170, 210, and $370 \mathrm{msec}$, respectively. Furthermore, the CSA-CSB intervals were $2,800,2,720,2,680,2,640$, and $2,480 \mathrm{msec}$, respectively. The order of stimulus presentation was counterbalanced so that four animals in each group received a tone-light series, and the other four received a light-tone series.

Each day of training consisted of 60 trials made up of 54 reinforced compound trials (CSA-CSB-US) interspersed with six nonreinforced test trials, each presented at intervals of 50,60 , and $70 \mathrm{sec}($ mean $=60 \mathrm{sec})$. The six test trials consisted of two presentations each of CSA-alone, CSB-alone, and the CSA-CSB series. A test trial was administered on every 10th trial, with the following restrictions: a test trial to each component and to the compound occurred no more than once in any 30-trial block, no two test trials of the same component or compound occurred adjacent to one another, and no sequence of six was repeated on adjacent days. A CR to CSA was defined as a response occurring with a latency less than $1,000 \mathrm{msec}$ after CSA onset. The duration of the scoring interval was set at $1,000 \mathrm{msec}$ to encompass responses elicited by CSA while minimizing the contribution of baseline, "spontaneous" responses. To include any responses occurring close to the temporal locus of the US (cf. Coleman \& Gormezano, 1971; Millenson, Kehoe, \& Gormezano, 1977; Sears, Baker, \& Frey, 1979), the scoring interval on CSA test trials was extended to $2,900 \mathrm{msec}$. Responses to CSB could not be measured on reinforced trials because their detection was frequently precluded by the occurrence of responses to CSA. Accordingly, responses to CSB were measured only on the two CSB test trials per session.

Experiment 3B. Following preparation and adaptation, the animals were assigned randomly to one of 10 groups and given 10 days of acquisition training. Five groups $(n=8)$ received $30 \mathrm{CS} 2$ CS1 trials interspersed with 30 CS1-US trials. The CS2-CS1 interval was $400 \mathrm{msec}$, and the CS2 duration was $400 \mathrm{msec}$. The CS1-US interval was $100,140,160,320$, or $400 \mathrm{msec}$. For expository purposes, the five groups were labeled as the "PP" condition to denote the first-order and second-order pairings. Half the animals in each of the PP groups received tone as CS2 and light as CS1, while the other half received light as CS2 and tone as CS1. The remaining five groups $(n=4)$ received $30 \mathrm{CS} 2$-alone, $30 \mathrm{CS} 1$-alone, and $30 \mathrm{CS} 1$-US trials. These groups received CS1US intervals of $100,140,160,320$, and $400 \mathrm{msec}$, respectively. The groups were labeled as the "PU" condition to denote the first-order pairings and the second-order unpairings. The PU groups received light as CS2 and tone as CS1. In both the PP and PU groups, the CS1 duration covaried with the CS1-US interval.

\section{Results}

\section{Experiment 3A (Serial Compound Conditioning)}

Figure 4 shows the percentage CRs to CSB for Groups S0, S80, S120, S160, and S320 across blocks of four test trials. Examination of the figure indicates that the course of CR acquisition to CSB varied as a direct function of the CSB-US interval, which agrees with what has been seen in previous research with single CSs (cf. Smith et al., 1969). Overall, the mean percent CRs to CSB for Groups S0, S80, S120, S160, 


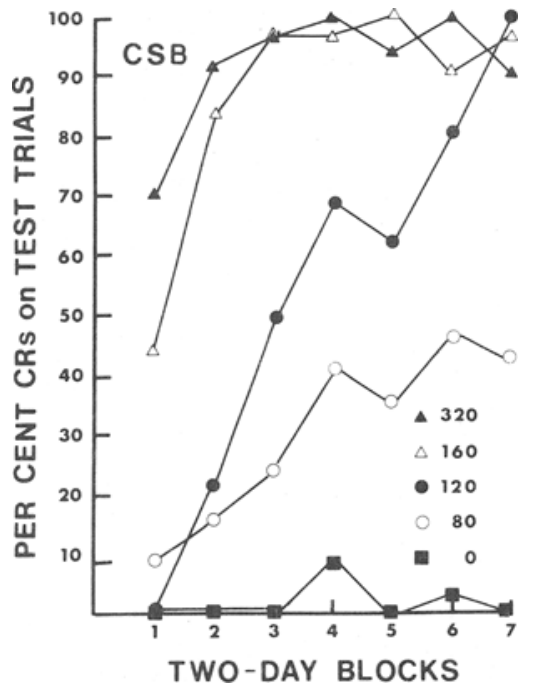

Figure 4. Mean percentage of CRs on CSB test trials plotted as a function of 2-day blocks for serial compound Groups SO, S80, S120, S160, and S320 in Experiment 3A. The group labels denote the CSB-US interval in milliseconds.

and S320 were $2 \%, 31 \%, 55 \%, 88 \%$, and $92 \%$, respectively. The positive relation between the level of responding to CSB and the CSB-US interval was confirmed by a significant linear trend in the overall means $[F(1,30)=128.31]$.

Figure 5 shows the mean percent CRs to CSA on reinforced trials for each group across training sessions. Figure 5 indicates that, as was the case for $\mathrm{CSB}$, the rate of CR acquisition to CSA varied as a direct function of the CSB-US interval. Specifically, Group S0 showed only a low frequency of responding to CSA, which never exceeded $18 \%$ CRs. Since Group S0 showed few CRs to CSB, the low level of responding to CSA can be construed as an estimate of direct conditioning of CS1 at the $2,800-\mathrm{msec}$ CSAUS interval, which was uniform across all groups. In fact, the estimate obtained in the present experiments nearly matches the low level of performance obtained by Kehoe et al. (1979, Experiment 2), who trained a single-CS control group at a 2,750 -msec CSA-US interval. In the other groups, even a low level of $C R$ acquisition to CSB produced a comparable level of CR acquisition to CSA. Specifically, Groups S80, S120, S160, and S320 showed progressively more rapid initial CR acquisition, which reached maximum levels of $36 \%, 64 \%, 72 \%$, and $70 \%$, respectively. After reaching a maximum, the level of responding to CSA began to decline slowly across sessions. The inverted-U shape of the CSA performance curves seen in all groups, except S0, was confirmed jointly by a significant quadratic trend in the means across days $[F(1,30)=54.86]$ and a nonsignificant linear trend $[F(1,30)=1.09]$. Furthermore, the graded dif- ferences between groups in the level of responding to CSA as a function of the CSB-US interval were confirmed by a linear trend among group means which interacted with a linear trend across days $[F(1,30)=$ 22.84]. Examination of the CSA test trials, which encompassed a longer, 2,900 -msec scoring interval, yielded an overall response level which was 10 to 20 percentage points higher than on reinforced trials. Nevertheless, the pattern of results was the same as seen on reinforced trials.

\section{Experiment 3B (Second-Order Conditioning)}

Figure 6 shows the mean percentage of CRs to CS2 (Panel a) and CS1 (Panel b) for each CS1-US interval as a function of 2-day blocks of training. Only the performance curves for the PP condition are shown. Figure 6 indicates that the level of responding to CS1 (Panel b) was a direct function of the CS1-US interval, which parallels the function obtained for CSB in the serial compounds used in Experiment 3A. Examination of responding to CS2 (Panel a) reveals that, under the 100-msec CS1-US interval, responding to CS2 was very low and then, at the longer CS1US intervals, the level of responding to CS2 increased sharply.

Parallels in the level of responding to CS2 and CS1 across CS1-US intervals can be more clearly seen in Figure 7, which shows the overall mean percentage CRs to CS2 and CS1 for the PP and PU conditions as a function of the CS1-US interval. Panel a shows the means for the animals in the PP condition which were trained with tone as CS2 and light as CS1. In Panel a, responding to both CS2 and CS1 showed levels that increased in a linear fashion across the CS1-US interval $[F s(1,15)=8.02$ and 46.53 , respectively]. Panel $b$ shows the mean for the animals in the

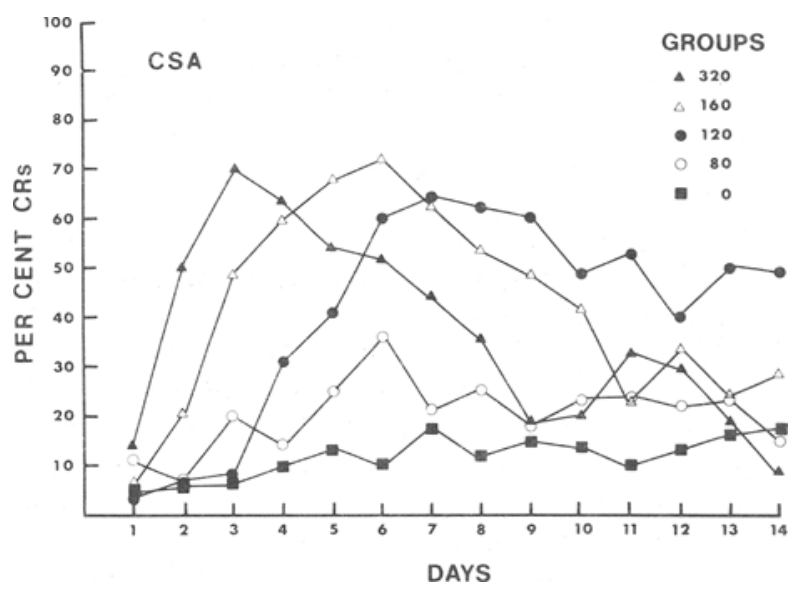

Figure 5. Mean percentage of CRs to CSA plotted as a function of days for serial compound Groups So, S80, S120, S160, and S320 in Experiment 3A. The group labels denote the CSB-US interval in milliseconds. 

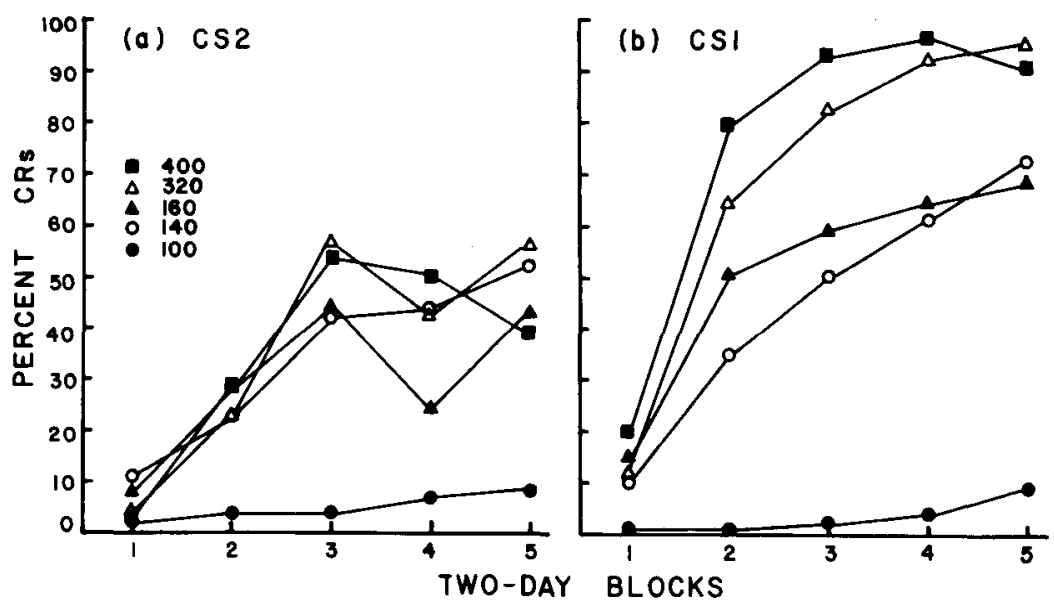

Figure 6. Mean percentage of second-order CRs to CS2 (Panel a) and first-order CRs to CS1 (Panel b) plotted as a function of 2-day blocks for Groups PP100, PP140, PP320, and PP400 in Experiment 3B. The group labels denote the CS1-US interval in milliseconds.

PP condition trained with light as CS2 and tone as CS1. In Panel b, the level of responding to CS2 and CS1 increased rapidly between the CS1-US intervals of 100 and $140 \mathrm{msec}$ and then was approximately constant across intervals of 140 to $400 \mathrm{msec}$. Similarly, in Panel c, which shows the means for the PU condition, responding to CS1 showed a sharp increase between the CS1-US intervals of 100 and 140 msec. As seen in Experiments 1 and 2, the level of responding to CS2 in the PU condition was generally low, means $<15 \%$ CRs, and showed, at best, a small increase as a function of the CS1-US interval. Statistical analysis of the data displayed in Panels $b$ and $c$ revealed that there was a reliable difference between the PP and PU conditions in responding to CS2 $[F(1,30)=37.52]$. The graded effects of the CS1-US interval manipulation on responding to CS2 in the PP condition was confirmed by a linear trend across the CS1-US interval which interacted with a quadratic trend across blocks of training $[F(1,30)=9.04]$.

\section{Discussion}

The present results revealed that (1) the level of responding to CSA and CSB in a serial compound both varied in parallel fashion as a function of the CSBUS interval (cf. Kehoe, 1979), and (2) the levels of responding to CS2 and CS1 in second-order conditioning both varied in a parallel fashion as a function of the CS1-US interval. In comparing the results of serial compound conditioning and second-order conditioning, there appears to have been a fair degree of concordance between the effects of the CSB-US and CS1-US interval manipulations. Furthermore, the effects of the CSB-US and CSI-US intervals agree with functions obtained in single CS conditioning with manipulations of the CS-US interval (Smith et al.,
1969). Thus, effects of parametric manipulations of CS-US contiguity observed in conditioning with a single CS can be used to predict in part, the strength of responding in multiple, serially presented CSs. The concordance between the effects of CS-US interval manipulations in serial compound conditioning and second-order conditioning indicates that the processes of associative transfer manifest themselves in a similar fashion in the two procedures. At a minimum, the initial acquisition of CRs to CSA and CS2 appears to depend quantitatively on the variations in the associative strength of the stimulus (CSB or CS1) most closely paired with the US.

\section{GENERAL DISCUSSION}

The present experiments provided repeated demonstrations of associative transfer with the rabbit NMR preparation and, at the same time, delineated the effects of interstimulus contiguity, that is, CS2CS1 and CS1-US, as a quantitative determinant of associative transfer. In Experiments 1, 2, and 3, comparisons between pairings vs. unpairings of CS2 with CS1 revealed that the level of CR acquisition to CS2 exceeded that attributable to stimulus generalization from CS1 to CS2. Moreover, Experiment 2 showed that a quantitative variation in the CS2-CS1 interval produced a contiguity gradient similar to that obtained in first-order conditioning with manipulations of the CS-US interval (cf. Gormezano, 1972; Smith et al., 1969). Thus, CR acquisition to CS2 clearly depended on CS2-CS1 contiguity. Similarly, the present experiments demonstrated that $\mathrm{CR}$ acquisition to CS2 also depended on contiguity between CS1 and the US. Specifically, Experiment 1 showed that when CS1 and the US were unpaired, there was no CR acquisition to either CS1 or CS2. Furthermore, in Ex- 

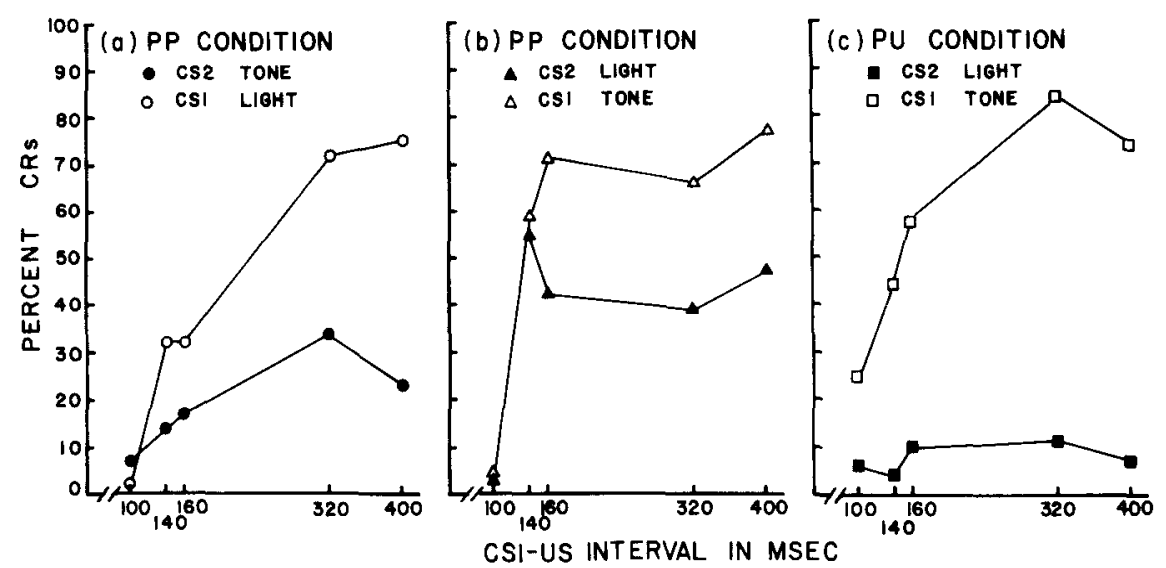

Figure 7. Mean percentage of second-order CRs to CS2 and first-order CRs to CS1 plotted as a function of the CS1-US interval in Experiment 3B. Panels a, b, and $c$ show the functions for animals in the PP (tone-light), PP (light-tone), and PU (light/tone) conditions, respectively.

periment 3, quantitative variations in the CS1-US interval produced parallel variations in the level of responding to CS2 and CS1.

The present experiments not only successfully demonstrated associative transfer, but also revealed that high and persistent levels of responding could be obtained. Under optimal parameters of $400-\mathrm{msec}$ CS2-CS1 and CS1-US intervals, which were replicated in Experiments 1, 2, and 3, responding to CS2 reached maximum levels of $60 \%, 66 \%$, and $54 \%$, respectively. While CR acquisition to CSA was not permanent, it typically continued for 180 CS2-CS1 trials distributed over 6 days before any sign of decline appeared. The robustness of the associative transfer becomes even more apparent when it is realized that the use of intermixed CS2-CS1 and CS1US pairings constitutes ideal conditions for conditioned inhibition (Herendeen \& Anderson, 1968; Pavlov, 1927, pp. 68-71, 1928, pp. 104-106; Popik et al., 1979).

The present results provide some support for hypotheses that processes of associative transfer make major contributions in serial compound conditioning (cf. Gormezano \& Kehoe, 1981, in press; Kehoe et al., 1979). Most generally, the use of intermixed CS2CS1 and CS1-US pairings from the start of training approximated the conditions prevailing in serial compounds. Thus, the acquisition of CRs to CS2 indicates that processes of associative transfer can operate reliably in conjunction with initial acquisition of CRs to CS1. In fact, an inspection of the secondorder and first-order conditioning curves in the present experiments reveals that, under optimal interstimulus intervals, the level of responding to CS2 began to rise on the same days that responding to CS1 began to appear. Furthermore, the similar effects of CS-US interval manipulations in Experiments $3 \mathrm{~A}$ and $3 B$ indicates that $C R$ acquisition to CSA in a serial compound depends on the associative relation between CSB and the US in the same way that CR acquisition to CS2 in second-order conditioning depends on the associative relation between CS2 and the US.

Despite the repeated demonstrations of associative transfer, the results of the CS2-CS1 interval manipulation in Experiment 2 suggests that processes of associative transfer are not entirely responsible for CR acquisition to CSA in a serial compound. In particular, the role of CS-CS contiguity appears to differ in serial compound conditioning and second-order conditioning. On one hand, Kehoe et al. (1979) showed indirectly that responding to CSA depended generally on the CSA-CSB sequence in the serial compound, for "uncoupled" CSA-US and CSB-US presentations produced levels of responding to CSA that were significantly lower than those obtained in a serial compound procedure. On the other hand, manipulation of the CSA-CSB interval over values ranging from 400 to $2,400 \mathrm{msec}$ produced uniformly high initial rates of acquisition to CSA. In contrast, the results of Experiment 2 with a second-order conditioning procedure indicated that responding to CS2 varied with respect to both (1) paired vs. unpaired presentations of CS2 and CS1 and (2) the CS2-CS1 interval over the values of 400,800 , and $2,400 \mathrm{msec}$. In summary, the steep gradient obtained with manipulation of the CS2-CS1 interval in second-order conditioning did not match the relatively uniform levels of performance observed across comparable CSACSB intervals in reinforced serial compounds.

Because of the divergence in the gradients produced by CS2-CS1 and CSA-CSB interval manipulations, it is necessary to reconsider the possible sources of responding in a serial compound. Among the processes that may operate in serial compound conditioning, stimulus generalization from CSB to 
CSA would appear to be a minor candidate. In Experiments 1,2 , and 3 , the level of responding to CS2 in the PU condition can be used as an estimate of the level of stimulus generalization from CS1 to CS2. Across the three experiments, the maximum mean levels were $20 \%, 13 \%$, and $18 \%$, respectively. Similarly, direct conditioning of CSA through CSA-US would appear to make a minimal contribution to responding to CSA. In Experiment $3 \mathrm{~A}$, the estimate of the level of direct conditioning of CSA obtained in Group S0 reached a maximum of $10 \%$ CRs. The low levels of responding attributable to stimulus generalization and direct conditioning agree with previous estimates of the magnitude of these processes (Gormezano \& Kehoe, in press, Experiment 5; Kehoe et al., 1979, Experiments 2 and 3). Consequently, there remain three plausible alternative hypotheses regarding the sources of responding to CSA in a serial compound: (1) Estimates of associative transfer are too low, perhaps due to inhibitory processes arising from the unreinforced CS2-CS1 presentations; (2) possible contributors combine in a synergistic, rather than independent, additive fashion; and/or (3) a process of serial stimulus mediation operates in a reinforced serial compound.

The present experiments were intended to demonstrate associative transfer with the rabbit and, more particularly, to delineate the effects of interstimulus contiguity on CR acquisition to CS2. The theoretical implications have been directed toward an identification of the processes operating in serial compound conditioning. Having done so, some consideration can be given to the implications of the present results for the various hypotheses regarding mechanisms of associative transfer. Recently, Rescorla $(1980$, p. 3) has distinguished three issues in connection with associative transfer and, more generally, associative learning: (1) the conditions of association, (2) the elements of an association, and (3) behavioral indices of associative strength. The present results can be examined with respect to the conditions of association and the behavioral indices of association, but it would be forcing matters to extend the present results to an identification of whether the elements of a second-order association are S-S or S-R in nature. Regarding the conditions of association, the results of the present experiments indicate clearly that the determinants of initial CR acquisition to both firstorder and second-order CSs parallel one another. In particular, the effects of the CS2-CS1 and CS1-US intervals were entirely predictable from the effects of CS-US interval manipulations. Regarding the behavioral indices of associative strength, Rescorla (1980, pp. 12-18) has obtained results using activity measures which suggest that the ability of a firstorder stimulus to produce second-order conditioning may be a more sensitive measure of associative strength than the response-evoking capability of the same stimulus. In the NMR preparation, the capacity of CS1 to reinforce a second-order CR appeared comparable to its CR-evoking capacity. In Experiment 3B, the rate of $\mathrm{CR}$ acquisition to CS2 was predictable from the rate of CR acquisition to CS1 over a range of CS1-US intervals. In summary, the present experiments indicate that it is possible, in the rabbit NMR preparation, to produce substantial and sustained levels of second-order conditioning, which follows the same laws of interstimulus contiguity as first-order conditioning with respect to both the CS2-CS1 and CS1-US intervals.

\section{REFERENCES}

Anderson, D. C., Plant, C., Johnson, D., \& Vandever, J. Second-order aversive classical conditioning. Canadian Journal of Psychology, 1967, 21, 120-131.

Best, P. J., Best, M. R., \& Mickley, G. A. Conditioned aversion to distinct environmental stimuli resulting from gastrointestinal distress. Journal of Comparative and Physiological Psychology, 1973, 85, 250-257.

Coleman, S. R., \& Gormezano, I. Classical conditioning of the rabbit's (Oryctolagus cuniculus) nictitating membrane response under symmetrical CS-US interval shifts. Journal of Comparative and Physiological Psychology, 1971, 77, 447-455.

Frey, P. W., Englander, S., \& Roman, A. Interstimulus interval analysis of sequential CS compounds in rabbit eyelid conditioning. Journal of Comparative and Physiological Psychology, $1971,77,439-446$.

Gormezano, I. Classical conditioning. In J. B. Sidowski (Ed.), Experimental methods and instrumentation in psychology. New York: McGraw-Hill, 1966.

Gormezano, I. Investigations of defense and reward conditioning in the rabbit. In A. H. Black \& W. F. Prokasy (Eds.), Classical conditioning II: Current research and theory. New York: Appleton-Century-Crofts, 1972.

Gormezano, I., \& Kehoe, E. J. Classical conditioning: Some methodological-conceptual issues. In W. K. Estes (Ed.), Handbook of learning and cognitive processes (Vol. 2). Hillsdale, N.J: Erlbaum, 1975.

Gormezano, I., \& Kehoe, E. J. Classical conditioning and the law of contiguity. In P. Harzem \& M. D. Zeiler (Eds.), Advances in analysis of behavior (Vol. 2) Predictability, correlation, and contiguity. Sussex, England: Wiley, 1981.

Gormezano, I., \& Kehoe, E. J. Stimulus selection and associative transfer in classical conditioning to serial compounds: Theory and data. In J. B. Sidowski \& H. Hake (Eds.), Conditioning, cognition, and methodology: Contemporary issues in experimental psychology. Hillsdale, N.J: Erlbaum, in press.

Herendeen, D., \& Anderson, D. C. Dual effects of a secondorder conditioned stimulus: Excitation and inhibition. Psychonomic Science, 1968, 13, 15-16.

Holland, P. C., \& Rescorla, R. A. Second-order conditioning with food unconditioned stimulus. Journal of Comparative and Physiological Psychology, 1975, 88, 459-467.

KEHOE, E. J. The role of CS-US contiguity in classical conditioning of the rabbit's nictitating membrane response to serial stimuli. Learning and Motivation, 1979, 10, 23-38.

Kehoe, E. J., Gibbs, C. M., Garcia, E., \& Gormezano, I. Associative transfer and stimulus selection in classical conditioning of the rabbit's nictitating membrane response to serial compound CSs. Journal of Experimental Psychology: Animal Behavior Processes, 1979, 5, 1-18. 
Maisiak, R., \& Frey, P. W. Second-order conditioning: The importance of stimulus overlap on second-order trials. Animal Learning \& Behavior, 1977, 5, 309-314.

Millenson, J. R., Kenoe, E. J., \& Gormezano, I. Classical conditioning of the rabbit's nictitating membrane response under fixed and mixed CS-US intervals. Learning and Motivation, 1977, 8, 351-366.

Millek, R. G. Simultaneous statistical inference. New York: McGraw-Hill, 1966.

Pavlov, I. P. Conditioned reflexes (trans. G. V. Anrep). London: Oxford University Press, 1927.

Pavlov, I. P. Lectures on conditioned reflexes (trans. W. $\mathrm{H}$. Gantt). New York: International Publishers, 1928.

Popik, R., Stern, S. D., \& Frey, P. W. Second-order conditioning: Different outcomes in fear and eyelid conditioning. Animal Learning \& Behavior, 1979, 7, 353-359.

Rashotte, M. E., Griffin, R. W., \& Sisk, C. L. Second-order conditioning of the pigeon's keypeck. Animal Learning \& Behavior, 1977, 5, 25-38.

Rescorla, R. A. Pavlovian conditioned inhibition. Psychological Bulletin, 1969, 72, 77-94.

Rescorla, R. A. Second-order conditioning: Implications for theories of learning. In F. J. McGuigan \& D. Lumsden (Eds.), Contemporary approaches to learning and conditioning. New York: Winston, 1973.

Rescohla, R. A. Pavlovian second-order conditioning: Studies in associative learning. New York: Wiley, 1980.

Sears, R. J., Baker, J. S., \& Frey, P. W. The eyeblink as a time-locked response: Implications for serial and second-order conditioning. Journal of Experimental Psychology: Animal Behavior Processes, 1979, 5, 43-64.

Seraganian, P. Extradimensional transfer in the easy-to-hard effect. Learning and Motivation, 1979, 10, 39-57.
Smith, M. C., Coleman, S. R., \& Gormezano, I. Classical conditioning of the rabbit's nictitating membrane response at backward, simultaneous, and forward CS-US intervals. Journal of Comparative and Physiological Psychology, 1969, 69, 226-231.

Szakmary, G. A. Second-order conditioning of the conditioned emotional response: Some methodological considerations. Animal Learning \& Behavior, 1979, 7, 181-184.

Wickens, D. D. Conditioning to complex stimuli. American Psychologist, 1959, 14, 180-188.

Wickens, D. D. Compound conditioning in humans and cats. In W. F. Prokasy (Ed.), Classical conditioning: A symposium. New York: Appleton-Century-Crofts, 1965.

Wickens, D. D. Classical conditioning, as it contributes to the analyses of some basic psychological processes. In F. J. McGuigan \& D. B. Lumsden (Eds.), Contemporary approaches to conditioning and learning. New York: Winston, 1973.

\section{NOTE}

1. In reports of previous research by the senior author, CSA and CSB in a serial compound were labeled as CS1 and CS2, respectively, to denote the temporal succession of the stimuli. However, in the present context of second-order conditioning, the denotations were changed to letters to avoid confusion with the opposite convention in second-order conditioning but still distinguish serial compound conditioning from second-order conditioning.

(Manuscript received December 13, 1980; accepted for publication February 23, 1981.) 